\title{
JUVENTUDE E CONTEMPORANEIDADE: POSSIBILIDADES E LIMITES
}

\author{
CARMEM ZELI VARGAS GIL SOUZA*
}

NOSSO TEMPO É UMA sociedade planetária cheia de possibilidades e riscos, em que as ferramentas da velocidade não são mais as pernas. Diversidade, mudança e fragmentação fazem da vida uma constante reflexão. Os sinais emitidos pela tradição estão agora em branco. Fazer escolhas, assumir o risco da decisão e responsabilizar-se pelas escolhas feitas são questões fundamentais que se colocam hoje para todos nós.

A juventude —uma categoria inventada pelos adultos- mantémse, mas os seus gostos, atitudes, sonhos e sentidos tornam-se cada vez mais difíceis de somatizar. A experiência social contemporânea marca as identidades juvenis com um profundo desejo de viver em grupo, fazer-se na relação com o outro. O eu é relacional e móvel para responder a uma contemporaneidade que exige flexibilidade (Melucci, 1992).

Se a sociedade contemporânea gera demandas amplas e complexas, não oferece os meios para a inserção dos jovens, que fazem, das práticas culturais, formas de expressão, convivência e, por que não, bandeiras de lutas.

As redes interativas dos jovens diversificam-se cada vez mais, com grande dispersão das identidades e projetos. Assim, muito se tem

* Mestre em Educação pela UFRGs/Brasil, professora da Faculdade de Ciências e Letras de Osório, FACOS/Rs/Brasil. E-Mail: carmemz@terra.com.br. 
para indagar sobre os jovens e os estudos têm mostrado grandes lacunas no entendimento da condição juvenil na sociedade contemporânea.

Este artigo é parte da pesquisa desenvolvida para dissertação de mestrado apresentada em 2003, no Programa de Pós-Graduação em Educação da UFRGS, sob orientação do Nilton Bueno Fischer. O trabalho empírico foi realizado com jovens de uma cidade do interior do Rio Grande do Sul, tendo como referenciais teóricos Alberto Melucci, Marília Sposito, José Antonio Pérez Islas e José Machado Pais, entre outros.

Trazem-se, neste texto, reflexões mais teóricas que sustentaram a pesquisa situando questões que emergiram na pesquisa empírica, como as condições sociais a que estão submetidos os jovens brasileiros diante da falta de trabalho, escola e da ausência da família. Portanto, num contexto marcado por inúmeras dificuldades e desafios, como os jovens estão construindo suas identidades e marcando espaços de sociabilidade que permitam a troca de experiências, o reconhecimento e a construção dos sentidos de presença (Carrano, 2003).

\section{JUVENTUDES}

A juventude tem-se constituído objeto de inúmeros estudos de diferentes perspectivas. Abordagens sociológicas, psicológicas, pedagógicas, antropológicas, analisam mudanças físicas, psicológicas e comportamentais que ocorrem nesse momento da vida. Muitos estudos sociológicos voltam-se para problemas comuns da juventude, como abuso de álcool e drogas, delinqüência, gravidez, vida escolar, entre outros. Ou seja, circulam idéias no cotidiano que associam a juventude à noção de crise, irresponsabilidade e problema social e que carecem de políticas públicas. No entanto, abordar a juventude, na normalidade do seu cotidiano é tarefa importante, caso se queira empreender uma reflexão sobre a sociedade atual.

Outro aspecto a considerar é a idéia de ter uma idade ou pertencer a uma idade. Lloret (1998) diz que os anos nos têm e nos fazem crianças, jovens, adultos ou velhos, e pertencer a um grupo de idade significa ter que se adequar a um conjunto de coisas que podemos ou não fazer. $\mathrm{E}$ a vida passa a ser graduada a partir da idade: idade escolar, idade do trabalho, idade militar, idade da rebeldia... Evidentemente, a idade adulta é proposta como a meta a ser alcançada, como diz Lloret: 
A postura ereta e a maior estatura do homem adulto configuram a imagem do modelo a alcançar em uma etapa ou ápice de máxima potência; precede-a outra que indica um presente reduzido, porém numa direção de crescimento; seguelhe a figura declinante do velho que parece anunciar o ocaso (Lloret, 1998:18).

A idade não é, então, somente um conjunto de anos que se vai agregando num processo linear, mas determina expectativas e comportamentos, podendo tornar o tempo um inimigo. Por outro lado, diz Lloret (1998:20) que, no devir das experiências e respostas existenciais, uma idade não elimina a outra, mas a contém. Em vez de se pensar na juventude como um momento de preparação para algo que está por vir, alimentando preconceitos e hierarquizações, acreditar que «o menino e a menina, o jovem e a jovem estão na pessoa adulta ou velha e, inclusive, os meninos e as meninas podem responder como adultos em determinadas situações».

Mas de quem se fala quando se usa o termo juventude? O termo aparece ao longo da história, mas seu conteúdo ganhou sentidos diferentes. Como salienta Levi e Schmitt:

De um contexto a outro, de uma época a outra, os jovens desenvolvem outras funções e logram seu estatuto definidor de fontes diferentes: da cidade ou do campo, do castelo feudal ou da fábrica do século XIX... Tampouco se pode imaginar que a condição juvenil permaneça a mesma em sociedades caracterizadas por modelos demográficos totalmente diferentes (Levi e Schmitt, 1996:17).

As Nações Unidas entendem os jovens como indivíduos com idade entre 15 e 24 anos. Mas o critério da idade não é suficiente para discutir uma categoria que assumiu contornos tão diferentes. Nem se pode percebê-la como grupo social homogêneo, pois se agrupam sujeitos que só têm em comum a idade. É preciso distinguir a fase da vida e os sujeitos, ou seja, não se pode misturar juventude e os jovens; o primeiro é a fase, e o segundo são os sujeitos que vivem uma diversidade. Qualquer reflexão supõe pensar a tensão entre a inserção na estrutura social e a fase da vida.

Sposito (1997), reconhecendo que a própria definição da categoria juventude encerra um problema sociológico passível de investigação, aponta que o modo como se dá a passagem - heteronomia da criança para a autonomia do adulto-, a duração e as características têm variado nos processos e formas de abordagem dos trabalhos que tradicionalmente se dedicam ao tema. Também, porque a estruturação das idades difere enormemente de uma sociedade a outra. Ariès (1981) 
fala que, no período pré-industrial, não existia a adolescência como é entendida hoje, e a infância não estava separada do mundo adulto. Aos sete/oito anos de idade, mandavam-se os filhos para a casa de outros como aprendiz. O sistema escolar não era de grande abrangência e não se tinha uma homogeneização institucional das classes de idade. Então, a categoria jovem poderia abranger indivíduos dos 6 aos 40 anos de idade.

Para Ariès (1981), são os humanistas e religiosos que proliferam, a partir do século XV, teorias e práticas que distinguem a infância da juventude e da vida adulta. Concomitantemente a isso, o crescimento do ensino que separa as crianças e jovens dos adultos. Emílio, de Rousseau, é a obra que vai produzir, em nível teórico, a concepção moderna de infância e adolescência —matriz do que será depois juventude- . A adolescência será definida por Rousseau como um segundo nascimento. Uma época, segundo ele, especialmente turbulenta, que deve ser constantemente vigiada. Essa concepção consolida-se no século XIX e, junto a ela, um interesse novo pela juventude, tempo também de turbulência, caracterizada por um excesso de paixão irracional que deveria ser vigiado e enclausurado.

Perceber a juventude como um momento da vida que marcaria a saída da infância até o ingresso no mundo adulto, vivido de forma homogênea, é ignorar as condições histórico-culturais dos integrantes desta categoria. Como anuncia Levi e Schmitt:

Essa «época da vida» não pode ser definida com clareza por quantificações demográficas, nem por definições de tipo jurídica, e é por isso que nos parece substancialmente inútil tentar identificar e estabelecer, como fizeram outros, limites muito nítidos (Levi e Schmitt, 1996:19).

Segundo Pais (1993), a juventude é uma categoria socialmente construída. Portanto, sujeita a modificar-se ao longo do tempo. A segmentarização do curso da vida em sucessivas fases é produto de um complexo processo de construção social. No dia-a-dia, os indivíduos tomam consciência de determinadas características e, se elas afetam um universo considerável de indivíduos pertencentes a uma geração, são culturalmente incorporadas. Se essas características de um período da vida apresentam-se como expressão de problemas, então atraem a atenção dos poderes públicos, tornando-se objeto de medidas legislativas ou não. Como exemplo, há os programas de formação profissional, prolongamento da escolaridade, a criação do Estatuto da Criança e do Adolescente e muitas outras. 
A idade, como critério para agrupar as pessoas, traz implícito o caráter da transitoriedade. Nesse caso, a juventude representaria uma transição, e ser jovem seria estar numa condição provisória. Como diz Melucci (1997), esse modo de ver a juventude como mera transição decorre de uma compreensão da vida adulta como estável em oposição à instabilidade juvenil, fato que não se sustenta hoje, pois a sociedade contemporânea é marcada pela incerteza, mobilidade, transitoriedade e abertura para a mudança. Os atributos tradicionais da juventude parecem ter se deslocado para além dos limites biológicos. Tematizando essa questão, Melucci escreve:

La juventud no es una condición enteramente biológica, sino que también es cultural. Los individuos no son jóvenes porque (o sólo porque) tengan una cierta edad, sino porque siguen unos ciertos estilos de consumo o ciertos códigos de comportamiento y vestimenta. Ahora, la adolescencia se prolonga mucho más allá de sus fronteras biológicas, y las obligaciones para con la vida adulta se posponen hasta después de los veinticinco e incluso de los treinta años (Melucci, 2001:138).

As razões apontadas pelo autor demonstram a dificuldade de responder questões relacionadas à identidade, pois as referências da sociedade tradicional, os momentos de trânsito —os ritos de passagem - não se configuram mais como possibilidade para qualquer definição de juventude. Num contexto cultural marcado por diferentes pertencimentos, interações planetárias, explosão de oportunidades para a experiência individual, as fronteiras entre juventude e maturidade, segundo Melucci, evaporaram-se.

Autores que trabalham com a temática da juventude, entre eles, José Machado Pais, Melucci, Peralva, Abramo, Dayrell, Carrano, Sposito, entre outros, trazem um novo significado para os estudos sobre a juventude, colocando o jovem como protagonista de um tempo de possibilidades. De promessa de futuro ao modelo cultural do presente.

Rompendo com a idéia de grupo homogêneo com características comuns a uma idade, é que esses autores falam em juventudes, buscando construir uma noção de juventude pela ótica da diversidade, pois o lugar e o trabalho não definem mais a identidade dos indivíduos. Muitos são os modos de ser jovem. Pais (1993) propõe o exercício de olhar a juventude em torno de dois eixos semânticos: como aparente unidade e como diversidade. 


\section{CONDIÇÕES SOCIAIS}

O século XX termina apontando para um futuro cuja única certeza que se tem é a da mudança. As tradicionais formas de ver o mundo foram desmontadas, e a racionalidade técnica dá lugar a outras formas de pensamento. Já não se trata mais de soluções acabadas, mas de inventar, em cada situação, novas possibilidades, em um mundo em transformação com idas e vindas, quebras e dobras, cortes e rupturas. Enfim, um tempo de grandes viradas...

Pais comenta que «os jovens desdobram-se em personagens possíveis de vários guiões de futuro, mas o futuro imaginado por eles assemelha-se a jardins labirínticos de sendas que se bifurcam» (Pais, 2001:8). As possibilidades e escolhas são múltiplas, embora nem sempre possíveis.

Diante da multiplicidade dos jovens, pode-se elaborar mapas provisórios das condições sociais nos diferentes contextos, pois a fluidez e a abertura estendem-se para vários aspectos da vida, e os dados demonstram que a racionalidade moderna parece não ter cumprido suas promessas de progresso e bem-estar.

No Brasil, a população jovem de 15 a 24 anos está em cerca de 34 milhões, ${ }^{1}$ ou 47 milhões na faixa etária de 15 a 29 anos, e os indicadores sociais que medem a desocupação da força de trabalho sugerem que as piores taxas de desocupação são encontradas no segmento populacional juvenil. Segundo Pochmann (2000), o desemprego juvenil aumentou na década de 90 numa proporção superior ao desemprego total. Os jovens representaram $62,2 \%$ no montante global dos que perderam emprego assalariado. Parece que as portas do primeiro emprego foram fechadas para os jovens brasileiros, em especial os oriundos de classes populares, o que representa um passo para a frustração e o desânimo.

A realidade da desocupação ou da ocupação precária transformou as relações da juventude com o sentido do trabalho, gerando muitas incertezas. Diante da baixa capacidade da economia brasileira em gerar postos de trabalho, resta aos jovens, principalmente das camadas mais pobres, os setores de serviços básicos (limpeza, segurança, garçom, etc.), muitas vezes postos não assalariados ou sem registro formal. Assim, a escassez de empregos torna os jovens um dos principais segmentos da população ativa mais fragilizados.

1 Dados provenientes do último Censo Brasileiro (IBGE, 2000). 
Os jovens de 15 a 24 anos, ${ }^{2}$ representam aproximadamente 25\% da população economicamente ativa do Brasil e são fortemente atingidos pelo desemprego. Na década de 90, a quantidade de desempregados nessa faixa etária foi multiplicada por três, e a ocupação reduzida em 2,9\%. Em 1989, o Brasil possuía um milhão de jovens desempregados; em 1998, 3,3 milhões (Pochmann, 2000).

Quanto à educação no Brasil, o Censo do IBGE de 2000 mostrou um aumento da taxa de escolarização que passou de 55,3\% para $78,8 \%$, ou seja, os jovens possuem hoje mais acesso à escolarização formal. Entretanto, as reprovações, as idas e vindas aumentam a defasagem idade-série. O mesmo Censo apontou que 52,6\% dos jovens, na faixa etária de 15 a 17 anos, estão matriculados no Ensino Fundamental que é destinado a crianças de 7 a 14 anos.

Outro aspecto a considerar é a mortalidade juvenil que, segundo Carrano e Dayrell (2002), no Brasil, 26 mil crianças e jovens entre 10 e 19 anos perdem a vida por causas múltiplas, tais como acidentes, suicídio, doenças relacionadas à gravidez e outros fatores mórbidos. Cerca de $70 \%$ das mortes de jovens estão relacionadas a homicídios, acidentes de trânsito e suicídios. Segundo estudo da UNESCO de 2000, denominado Mapa da violência III, o Brasil ocupa o terceiro lugar do mundo no que se refere a assassinato de jovens entre 15 e 24 anos.

Os dados apontam para um descaso do Estado brasileiro, entregando uma geração a práticas de violência, muitas vezes ligadas ao narcotráfico. As políticas públicas voltadas à juventude não existem ou estão fora de foco (Carrano e Dayrell, 2002), pois são formuladas sem definição da população prioritária. A perspectiva compensatória é a tônica das políticas que usam as práticas esportivas e culturais estético-criativas como corretivos morais de contenção de drogas e crime. Numa visão da juventude como transição, oferecem entretenimento, enquanto a juventude não passa. Ponce de Leon diz que «o problema não é somente a insuficiência e a ineficácia dos programas do governo

2 Neste texto, os dados são apresentados a partir de diferentes faixas etárias, pois os indicadores estatísticos disponíveis no Brasil trabalham com divisões diferentes. O IBGE publica seus dados do Censo e da Pesquisa Nacional por Amostra de Domicílios (PNAD) agregando as faixas etárias de 10 a 14, 15 a 19 e de 20 a 24. As estatísticas educacionais privilegiam as faixas etárias correspondentes aos níveis de ensino: 7 a 14, 15 a 18. A população Economicamente Ativa (PEA), inclui crianças de 10 anos, sendo que a legislação em vigor proíbe o trabalho para menores de 14 anos, facultando-o para pessoas entre 14 e 16 anos na condição de aprendiz. 
federal, mas também, a falta de integração entre eles e a completa exclusão dos jovens e de suas organizações do processo de decisão» (Ponce de Leon, 2002:34).

Abramo (1997), analisando a juventude no Brasil, afirma que, apesar de terem sido alçados à categoria de problemas sociais, os jovens não têm ocupado o mesmo espaço na formulação das políticas públicas e que são raras as experiências que os consideram como interlocutores significativos. Em geral, as políticas são feitas da ótica do adulto e não da ótica dos direitos da juventude.

O quadro de incertezas acentua a indefinição dos jovens ao ingressarem no mundo adulto. Carrano comenta que:

O fenômeno social da já denominada geração canguru - jovens que seguem morando com os pais e não vêem perspectivas de sair de casa, mesmo com a união conjugal ou a gravidez-, evidencia o quadro de restrição «voluntária» da autonomia [...] A passagem à vida adulta estava fundada no princípio da concordância necessária de três significativos momentos: o início da vida profissional, o matrimônio e a saída da família de origem. Os jovens encontramse confinados num retalhado espaço social entre a família e a vida social autônoma, vivendo uma sociabilidade que se coloca entre duas idades: entre a idade centrada exclusivamente na família e na escola, e uma outra orientada pela vida da união sexual e das relações de trabalho (Carrano, 1999:116).

Pais analisa que os caminhos de passagem para a vida adulta não são apenas obscuros.

São caminhos longos, sinuosos, com escolhos. De fato, assiste-se, na sociedade contemporânea, a um prolongamento da condição juvenil: porque os percursos escolares são mais longos, porque há mais tardia inserção no mercado de trabalho; porque o acesso à casa própria é difícil; porque os casamentos retardam, devido também a uma maior liberalização das relações sexuais (Pais, 2001:81).

Os mapas de orientação dos jovens nem sempre combinam com os percursos. Por exemplo, às expectativas criadas pelo prolongamento da escolaridade, contrapõe-se a desqualificação dos diplomas. Assim, perante as estruturas sociais fluidas, os jovens sentem as inconstâncias e vivem num autêntico movimento de vaivém: abandonam os estudos e, depois, retornam; encontram emprego e, logo depois, estão desempregados; suas paixões são como vôos de borboletas, sem pouso certo; casam-se, mas não é certo que seja para toda a vida. Segundo Pais, «é porque vivem em estruturas sociais crescentemente labirínticas que os jovens contemporâneos se envolvem em trajetórias ioiô» (Pais, 2001:68). 
É preciso afirmar que qualquer política pública destinada à juventude necessita da ampliação do entendimento dos modos de ser jovem e um escuta sensível para a construção da participação juvenil, pois os impasses do presente não podem transformar o futuro num tempo ausente. Se a previsão navega nas águas da incerteza, o futuro precisa ser construído de forma participativa, envolvendo os jovens. E, como afirma Pais, «somente a esperança permite suportar a espera da sua chegada» (Pais, 2001:419).

\section{IDENTIDADES}

Foi-se o tempo em que se pensava que alcançar a cidade remeteria alguém para a liberdade prometida. Nela estaria autonomia e a livre afirmação pessoal. Mudava-se de lugar e construía-se uma nova identidade. Para que os ares da cidade se tivessem tornado palco de novas identidades, foi preciso pensá-la como mediadora entre a estrutura social e a ação dos sujeitos, feita e refeita ao sabor das mudanças.

Para Fortuna: «eminentemente relacional e interativa, perante a crescente complexidade das sociedades, a identidade moderna mostrase contingente e remete-nos para uma estrutura pessoal, afetiva e cognitiva que é progressiva e continuamente (re)construída pelos sujeitos» (Fortuna, 1997:128).

Se a vida é tecida na trama de relações que se vai construindo no decorrer do tempo, o conceito de identidade não pode comportar isolamento, fixação, estabilidade ou dualismo. A modernidade tentou buscar uma identidade estável, tal como um relógio, com peças fixas e movimentos previsíveis.

Hoje, mais do que um dado ou uma herança, pode-se falar de identidade como capacidade de reconhecer os efeitos de uma ação, o que Melucci (1992) chama de capacidade de reflexão sobre nós mesmos, ligada a um reconhecimento recíproco entre nós e os outros, o que abre um campo de conflito entre a definição que nos damos e o reconhecimento que os outros nos dão.

Para o jovem, a busca da idade adulta exemplifica essa tensão entre o auto-reconhecimento e o ser reconhecido, não esquecendo, como salienta Melucci (1992), a necessidade que se tem de afirmar a diferença enquanto indivíduo ou grupo. Nesse sentido, ele apresenta quatro pólos de nossa identidade: a identificação que nós operamos, a identificação por parte dos outros, a diferença como nós afirmamos e a diferença como nos é reconhecida pelos outros. Assim, ninguém cons- 
trói sua identidade sozinho, independente do olhar do outro. A identidade é, antes de tudo, uma aprendizagem constante que liga continuidade e mudança, estabelecendo entre ambas um processo relacional que distingue e une o indivíduo.

Pensando essas considerações em conjunto com os efeitos de viver num mundo globalizado, é possível pensar que as relações entre adultos e jovens estariam se desprendendo de um controle único, baseado na transmissão da experiência aos mais jovens. A socialização dos jovens está se produzindo em outros ambientes, onde as trocas culturais criam novos estilos de se vincular ao mundo, de decidir e de enfrentar os problemas. Ou seja, ampliam-se as possibilidades de reconhecimento. Obviamente, nem todos têm acesso a essa tecnologia e podem estar numa situação privilegiada para acessar os ditos espaços. ${ }^{3}$

Nesse contexto, os múltiplos pertencimentos dos sujeitos estruturam a identidade, tanto individual quanto coletiva e, como diz Melucci (2001), a identidade se constrói a partir de experiências comuns que se confrontam.

O processo de identificação não é estático e ocorre num mundo marcado pela complexidade no qual, constantemente, precisa-se fazer escolhas, reduzir as possibilidades e, conseqüentemente, aumentar a incerteza. Aqui, novamente Melucci (1992), dizendo que a liberdade de escolha e as possibilidades revelam que o tempo é escasso demais para tantas opções, e as condições materiais também não estão em sintonia com as ofertas do mercado. Tudo isso estabelece um campo de frustrações.

A identidade é, portanto, um processo de negociação constante cujo desafio é viver tecendo a trama da continuidade. Se a certeza escapa, a necessidade de se tornar reflexivo e aprendente torna o presente um momento de máximo encanto, em que a identidade se faz aqui e agora e na experiência.

Melucci (1992) considera a identidade individual uma das chaves para a compreensão das mudanças do indivíduo em uma sociedade complexa. Primeiro, analisa que as mudanças nas relações sociais alteram interesses e aspirações dos indivíduos; segundo, que a experiência do indivíduo participa desse processo e o modifica.

3 Evitando generalizações, considero, também, que muitos jovens de camadas empobrecidas têm buscado diferentes formas de visibilidade na cena pública. Nesse sentido, a tese de Dayrell (2001) sobre o rap e o funk, em Belo Horizonte, é um belo exemplo de jovens que, diante dos limites econômicos, desvelam novos modos de ser jovem. 
Procurando superar uma visão determinista da identidade, apresenta, como desafio, a construção da continuidade na mudança, chegando a propor a substituição do conceito de identidade pelo de identização, com o objetivo de «exprimir o caráter processual, auto-reflexivo e construído da definição de nós mesmos» ou, como diz Giddens, cada vez mais precisamos tomar conta de nossas próprias vidas, o que envolve risco, porque temos que enfrentar a diversidade de possibilidades abertas. «O indivíduo deve estar preparado para fazer uma ruptura mais ou menos completa com o passado, se necessário, e deve contemplar novos cursos de ação que não podem ser guiados simplesmente por hábitos estabelecidos» (Giddens, 2002:72). Sposito (1997) considera o momento da juventude rico em manifestações de sociabilidade, sendo as formas grupais fluidas mais expressivas do que a lógica racionalinstrumental voltada para um fim imediato. Salienta que é importante perceber como os jovens ocupam os espaços da cidade, agrupam-se e redefinem constantemente sua identidade. Nesse sentido, a música, a poesia, o teatro, a dança centralizam os interesses dos jovens como formas grupais que vão além do fazer parte de um grupo por interesses comuns. É, sim, condição para reconhecer o sentido daquilo que fazem. No grupo, afirmam o que são a partir do reconhecimento do outro.

Para os jovens pesquisados, o grupo é o espaço da visibilidade, da sua constituição como sujeito social, significando uma ampliação das redes de amizade, num exercício de convivência social que reforça a auto-estima e os coloca na cena pública, exercendo uma identidade reconhecida e desejada no grupo e que põe em relevo potencialidades pessoais.

No enfoque trazido por Melucci (1992), a noção de identidade torna-se importante para este trabalho, pois o caráter processual permite compreender a dinamicidade das experiências juvenis, em que os grupos são espaços privilegiados de construção de identidades. Possibilita pensar o grupo como espaço de ação, de reconhecimento e de convivência coletiva, no qual ampliam as relações e constroem identidades positivas. Obviamente que nem todos os grupos juvenis cumprem esse fim, mas é uma potencialidade que precisa ser acolhida e incentivada.

\section{TEMPO E JUVENTUDE}

No dizer de Furter, quando o homem toma consciência de que é um ser temporal, descobre o valor da espera de algo que poderá satisfazer 
as necessidades que sente. Mas o homem é, além de inacabado, «um ser que tem fome, que sente, todos os dias, que tem vazios e que nunca poderá comer bastante para estar definitivamente satisfeito» (Furter, 1987:96). Por isso, a esperança é a garantia do possível, da aceitação radical da existência como campo de possibilidades abertas à ação. É um sonhar acordado, porque «quando o homem está sonhando acordado, não está tanto fugindo ao mundo quanto imaginando um outro mundo» (Bloch, ${ }^{4}$ apud Furter, 1987).

Nosso tempo se desenvolveu sob o impacto da ciência, da tecnologia e do pensamento da racionalidade instrumental que teve origem na Europa dos séculos XVII e XVIII. Nesse momento, a modernidade anunciava o processo de industrialização impulsionando a sociedade capitalista, que traz uma figura de tempo baseada na máquina e na meta. Tudo passa a ser dividido, medido e calculado para se chegar à sociedade do progresso. Melucci (1992) afirma que a época moderna traz a imagem do tempo como um percurso linear, cujo sentido está no fim do caminho, ou seja, neste percurso linear de orientação finalista, a meta é o progresso final. De algum modo, essa orientação garantia certa unidade e continuidade para as experiências e um toque de certeza para a vida.

Em outros tempos, a água, a areia, o fogo, o vento, a luz do sol, eram as medidas de tempo cuja passagem era materializada pela transformação destes elementos.

Os relógios transformaram o tempo em percurso abstrato. Referindo-se aos relógios digitais, Melucci assinala que «o tempo é agora pura leitura de sinais e de elaborações cognitivas abstratas» (Melucci, 1992:9). Mas para ele, a nossa experiência do tempo interno não coincide com aquilo que decreta o relógio, pois o tempo que acompanha os afetos e emoções é múltiplo e descontínuo e na «experiência subjetiva tempos diversos coexistem, sucedendo-se, interceptando-se e sobrepondo-se». Aponta, nesse sentido, que a linearidade é difícil, pois o futuro está contido no passado, ou seja, o que fomos não pode ser cancelado e o que seremos reelabora o que fomos. Assim, o passado impregna o presente, mas o presente ressignifica o passado. A relação é, então, circular e não linear.

A sociedade da informação, cuja linguagem principal é a imagem, provocou rupturas no tempo, tornando possível fazer várias coisas em fração de segundos. Navega-se por mares desconhecidos sem

4 Ernest Bloch (1962): Das Prinzip Hoffnung, V. I e II. Frankfurt A. M. 
se sair do espaço onde se encontra. É um tempo marcado pela diversidade: diluído, acelerado, fragmentado e instantâneo. Ritmos que requerem uma adaptação e flexibilidade às vezes oposta ao tempo interno. Melucci insiste:

As diferenças entre os tempos internos e os tempos sociais não são uma novidade das culturas. Mas nas sociedades do passado, a relativa homogeneidade e a lentidão das mudanças garantiam uma certa integração entre a experiência temporal subjetivamente vivida e as definições do tempo reguladas socialmente (Melucci, 1992:14).

Hoje, a diferenciação, os múltiplos pertencimentos sociais e a aceleração das mudanças tornam difícil a unidade e o limite entre a procura de si, e a perda de si é tênue.

Melucci (1992) fala do nosso tempo como um tempo de muitas possibilidades, às vezes além do que se pode viver. Para ele, a liberdade de escolher e a embriaguez das possibilidades abertas revelam que o tempo é escasso, que se deve deixar para trás algumas coisas e isto se torna motivo de frustração. Segundo ele, os problemas advindos dessa escassez de tempo, necessidade de escolha e renúncia, são de três ordens: cancelamento do futuro: as possibilidades são muitas, as mudanças são rápidas e deixamos que o passado inunde o presente até cancelar o futuro; cancelamento do passado: muitas possibilidades e mudanças, é preciso perseguir tudo, não perder nada; tensão e estresse é a resposta do corpo para a falta de tempo e a ameaça de perder possibilidades porque não se volta para ressignificar o passado; e cancelamento do presente: que pode ser de duas formas: debruçados sobre aquilo que deve ainda vir, a ânsia ocupa o presente e fica-se imóvel; ou diante do temor de perder alguma possibilidade, perde-se o significado de cada uma, e o presente esvazia-se em desejos sem desejo, um tédio ocupa as pessoas.

O desafio, hoje, parece ser o de encontrar os fios para tramar a continuidade, construindo uma experiência de tempo que possibilite passar pela variedade e pela mudança sem se perder.

Os jovens vivem intensamente as contradições deste tempo, pois as incertezas próprias da idade são agravadas pelas incertezas desta época, tendo em vista que as referências para a compreensão do tempo —a medição pela máquina e a orientação finalista - dissolvem-se. Cada vez mais, convive-se com tempos marcados pela subjetividade, fragmentação e ritmos diferenciados. Melucci (1997) faz uma bela reflexão a respeito dos efeitos ancorados no futuro dessa quebra das 
referências temporais. Diz que esse processo também impede, de modo mais homogêneo, o trânsito para a vida adulta. Pais (2001), nesse aspecto, refere-se aos jovens dos anos 90 como geração ioiô, no sentido de que as referências tradicionais de transição para a vida adulta —abandono da família de origem, casamento, obtenção de empregosão reversíveis. Segundo Pais,

A geração ioiô, pela sua natureza, é uma geração em que o 'tempo flecha' se cruza com o tempo cíclico, tempo de eterno retorno. Os jovens dessa geração tão rapidamente abandonam a escola, adquirem emprego e se casam — deixando de ser jovens e passando a ser adultos— quanto, com a mesma rapidez, caem de novo no desemprego, voltam à condição de estudante e se divorciam, redescobrindo a juventude (Pais, 2001:73).

Assim, nesse momento da vida, os desafios para a construção das identidades tornam-se mais fortes, e a busca pela resposta às perguntas quem sou, como me aproximo e me diferencio do outro, torna-se presença constante. Obviamente essa busca acompanha todos durante a vida, mas esse momento representaria viver intensamente processos que continuarão sendo companheiros, matizando vidas com tons de prazer e dor, certeza e insegurança.

Segundo Carrano (2002), a transformação do relacionamento com o tempo caminha em conjunto com os adolescentes contemporâneos. Até mesmo os grupos urbanos com características agressivas multiplicam os referenciais de tempo, produzindo um nomadismo urbano dos indivíduos radicados por tempos relativamente breves e em espaços específicos.

As viagens virtuais e os encontros eletrônicos são possibilidades culturais que alargam o território dos jovens para outros limites de tempo e espaço. O território passa a ser o mundo inteiro.

A sociedade da informação redefine, então, os conceitos de tempo e espaço. Perto e longe tornam-se dimensões simbólicas. As imagens são o meio de transporte para espaços que diferem da experiência física. Com rapidez, alcançam-se diferentes partes do globo terrestre. Surge uma geografia da mente. Giddens analisa a separação de tempo e espaço na modernidade 5 que, segundo ele, gerou o desenvolvimento

$5 \quad$ No livro Modernidade e identidade, Giddens (2002:21) utiliza o termo modernidade num sentido muito geral para referir-se às instituições e aos modos de comportamento estabelecidos na Europa depois do feudalismo, mas que, no século Xx, tornaram-se mundiais em seu impacto. Para ele «a 'modernidade' pode ser entendida como aproximadamente equivalente ao 'mundo industrializado', desde que se reconheça que o industrialismo não é sua única dimensão institucional». 
de uma dimensão vazia de tempo e separou o espaço do lugar. O mapa global, sem privilégio de lugar, é o símbolo correlato do relógio no esvaziamento do espaço. «Não é apenas um modo de retratar 'o que sempre esteve lá' —a geografia da terra—, mas também constitutivo de transformações básicas nas relações sociais» (Giddens, 2002:23). Ele chama de desencaixe esse deslocamento das relações sociais dos contextos locais e sua rearticulação pelas partes indeterminadas do espaço-tempo.

Tempo e espaço constituem-se múltiplos e descontínuos e exigem de nós elasticidade, mudança, conexão e capacidade de conviver cotidianamente com a incerteza. Segundo Melucci (1992), nos locomovemos mais, e mais rapidamente do que no passado, mas com a impressão de girar em círculo, pois nos movemos livremente embora não conheçamos as coordenadas do território e, então, é indiferente saber onde estamos.

Neste mundo desterritorializado, o espaço geográfico é substituído pelo tempo dos fluxos de informações. Esse espaço de fluxos permite conhecer outras culturas, trocar idéias, ampliar a rede de contatos e fazer novas escolhas. Para os jovens, essa redefinição das coordenadas espaço-temporais pode alterar o sentido do grupo, no qual o pertencimento a um determinado grupo pode se tornar uma escolha temporária e variável. Carrano comenta que «o fundamento da nova solidariedade da juventude não se encontraria numa simples adesão ao já dado, mas na capacidade e na responsabilidade de escolher» (Carrano, 2002:102). Mas se o tempo atual permite uma variedade de escolhas, oferece pouca ajuda sobre as opções que devem ser selecionadas. Giddens anuncia que «falar em multiplicidade de escolhas não é o mesmo que supor que todas as escolhas estão abertas para todos, ou que as pessoas tomam todas as decisões sobre as opções com pleno conhecimento da gama de alternativas possíveis» (Giddens, 2002:80).

Os fenômenos juvenis contemporâneos comportam um entrelaçamento do coletivo e do individual, constituindo a chave para compreender o que acontece nos grupos da juventude, pois as experiências dos jovens são construídas, em grande parte, nas redes de relações e no significado da cultura global. Compondo com Margulis e Urresti (1998), os jovens aterrizam no presente e nele formam sua personalidade, constroem sua cultura e organizam seu ritmo de vida, mergulhados num tempo de incerteza. Tempos ziguezagueantes (Pais, 2001) e velozes são tempos de contratempos. São muitos desses contratempos que caracterizam a condição juvenil contemporânea. 
Se a incerteza caracteriza os jovens e tem um prefixo negativo, este sugere, também, abertura ao possível. Portanto, juventude é incerteza e possibilidade. Melucci (2001) fala das experiências dos jovens como enormes laboratórios de inovações, não por que as projetam, mas por que já as praticam. No mesmo sentido, Carrano (2002) diz que para os jovens o fundamental não é a construção de metas para um futuro, mas a experimentação do sentido de mudança presente. Por outro lado, os jovens correm o risco da glorificação de um presente sem limites, pobre de memória e carente de futuro. Entretanto, Melucci (1992) anuncia que a consciência do limite, o cansaço de superá-lo, a percepção da falta e da perda dão raízes à possibilidade de aceitar o presente e de projetar o futuro, assumindo a responsabilidade perante o outro e perante a si mesmo.

\section{SOCIALIZAÇÃO E SOCIABILIDADE JUVENIL}

\section{Socialização}

Durkheim trouxe a clássica formulação da socialização como meio integrador, no qual as regras sociais são transmitidas às novas gerações pelo processo de educação. Diz que, ao nascer, o indivíduo já encontra a sociedade pronta e constituída em suas leis. Para ele, a educação é, na verdade, um meio pelo qual a sociedade prepara, no íntimo das crianças, as condições essenciais de sua própria existência. Considerava a sociedade como um sistema formado pela associação de indivíduos que se manifesta como um fato objetivo, externo a nós, que determina quase tudo que se faz. A sociedade nos precedeu e nossas vidas não passariam de um episódio na marcha do tempo.

Outros autores, como Berger e Luckmann (1985), falam dos limites da sociologia clássica para a compreensão dos processos de socialização contemporâneos, pois explicar a socialização por meio da reprodução, pela qual tudo é interiorizado numa posição objetiva, limita e predetermina as ações dos indivíduos.

Berger (1999) fala da socialização como um processo de internalização. O mundo social é internalizado pela criança, mas este processo também ocorre com o adulto cada vez que é iniciado num novo contexto social ou num novo grupo social. Esses dois processos, Berger e Luckmann (1985) definem como socialização primária, no primeiro caso, e socialização secundária, no segundo caso. A sociedade não é, então, algo que exista lá, no sentido durkheimiano, mas parte do nosso ser mais 
íntimo. A sociedade não só controla nossos movimentos como dá forma aos nossos pensamentos, identidades e emoções. Segundo Berger, «as paredes de nosso cárcere já existiam antes de entrarmos em cena, mas nós a reconstruímos eternamente. Somos aprisionados com nossa própria cooperação» (Berger, 1999:136). Nesse sentido, Berger e Luckmann analisam a socialização como construção social, vivência singular, seja na família, escola, trabalho, seja em qualquer instituição. Significa movimento, pois, segundo eles, «a socialização nunca é total nem está jamais acabada» (Berger e Luckmann, 1985:184).

Nessa direção, Dubet ${ }^{6}$ (apud Dayrell, 2001) diz que, nas sociedades em mutação, os atores e as instituições não são mais redutíveis a uma lógica única. $\mathrm{O}$ ator não é totalmente socializado a partir das orientações das instituições nem a sua identidade é constituída apenas nos marcos das categorias do sistema. Ou seja, o ator não pode ser reduzido à interiorização do social. Passa a ocorrer uma multiplicidade de processos culturais e sociais que organizam as ações dos atores, podendo adotar simultaneamente vários pontos de vista.

Melucci (2001) discute que, nas sociedades complexas, na qual a informação assume a centralidade, as experiências constitutivas do sujeito são, cada vez mais, permeadas pela tensão entre limite e possibilidade, entre o pleno e o vazio. $\mathrm{O}$ eu não tem mais uma base sólida de uma identificação estável, e as seguranças de que necessitamos devem ser construídas por nós mesmos. As agências clássicas de socialização se mostram frágeis e nenhuma delas, no contexto de uma sociedade em constante transformação, oferece um porto seguro.

Para a juventude contemporânea, o processo de socialização é composto de múltiplas interações, compondo uma trama que, ao mesmo tempo, abre muitas opções e, também, muitos limites. Tendo acesso a múltiplas referências culturais, os jovens criam sentidos para as experiências que vivenciam e se constituem como sujeitos a partir destes processos. Impossível, portanto, pensar isso numa lógica determinista, com a socialização reduzida a um treino que propicia a interiorização de regras e valores.

\section{Sociabilidade}

Freire (1999) dizia que, onde há vida, há o inacabado, e que nossa presença no mundo não se faz no isolamento, isenta de influências. E

6 Francois Dubet (1994): Sociologie de I'eperience. Paris: Editions du Seuil. 
para Charlot, «nascer significa ver-se submetido à obrigação de aprender. Aprender para constituir-se [...]. Aprender para viver com outros homens com quem o mundo é partilhado» (Charlot, 2000:53). Nesse sentido, a influência do meio sobre o indivíduo humano inacabado é um processo relacional e, portanto, não se está somente posicionado em..., mas em relação com... Aprender na relação com o outro, viver em grupo é o grande desafio posto a todos.

Os jovens pesquisados encontram-se em grupos, mas há um vínculo desses grupos com o espaço social em que estão inseridos. Nessa interação, constroem suas experiências cotidianas, que giram em torno de expressões culturais, num processo educativo vital para a juventude. Durand (2000) considera a sociabilidade parte do processo de socialização vivenciado pelos jovens em seus grupos, como um lugar privilegiado das escolhas, da construção de sentidos, da solidariedade e da construção da autonomia.

Simmel, em seu estudo sobre sociabilidade como categoria sociológica, diz que essa é uma forma autônoma ou lúdica de sociação. ${ }^{7}$ Fala do lúdico, em primeiro lugar, porque o que conta não é um objetivo a ser atingido ou a busca de resultados concretos. Segundo ele:

A sociedade propriamente dita é o estar com o outro, para um outro, contra um outro que, através dos veículos, dos impulsos ou dos propósitos, forma e desenvolve os conteúdos e os interesses individuais. As formas nas quais resulta esse processo ganham vida própria. São liberadas de todos os laços com os conteúdos; existem por si mesmas e pelo fascínio que difundem pela própria liberação destes laços (Simmel, 1983:168).

Para Simmel (1983), a sociabilidade é uma forma de sociação, cujo fim é a própria relação, ou seja, os laços estabelecidos entre os indivíduos têm uma razão em si mesmos. Na pureza de suas manifestações, a sociabilidade não tem propósitos objetivos, conteúdo ou resultados exteriores. Seu alvo é o sucesso do momento sociável.

7 Simmel chama de sociação a unidade que resulta das interações entre os indivíduos. Tais interações acontecem por objetivos específicos (religiosos, eróticos, lúdicos, violentos, etc.). $\mathrm{O}$ indivíduo é influenciado e influencia essas interações. $\mathrm{O}$ resultado dessas múltiplas interações é a sociação, a unidade. A composição de cada grupo de interações cria uma sociação específica. Já a sociabilidade é uma forma lúdica de se relacionar com outro indivíduo e a relação está centrada no prazer da conversa, da troca, da convivência. A sociabilidade perde essa dimensão quando se transforma numa discussão séria ou numa verificação da verdade dos fatos comentados. Isso não significa que a sociabilidade é uma interação indiferente. Ela precisa ser uma interação interessante, significativa, agrupadora. 
Simmel formula o seguinte princípio para a sociabilidade: «cada indivíduo deveria oferecer o máximo de valores sociais (de alegria, de realce, de vivacidade, etc.) compatível com o máximo de valores que o próprio indivíduo recebe» (Simmel, 1983:172).

Contemporaneamente, há um processo de redefinição das formas de sociabilidade, que se tornam fluidas, abertas e movediças, diferentes das formas tradicionais que eram mais estáveis. Hoje, as pessoas desempenham uma grande diversidade de experiências, podendo pertencer a uma ou mais coletividades, simultaneamente ou não. Porém, o sentido para esse pertencimento, segundo Simmel, não estaria no conteúdo da relação, na satisfação de interesses, mas na própria relação. Ou seja, no campo da sociabilidade, o estar juntos, estabelecer laços, tem em si mesmo a sua razão de ser. Portanto, se não existe outro interesse além da própria relação, para que ela continue existindo, é preciso confiança mútua. Em parte, essa idéia poderia ser associada à grande mobilidade dos agrupamentos juvenis, principalmente as bandas de música que mudam constantemente de integrantes.

Para Simmel, a realidade da vida social se constrói no âmago da interação entre os homens: o processo de sociação comporta a dinâmica de um jogo pelo qual os homens fazem sociedade. Nesse jogo, está presente a dimensão do conflito inerente às relações humanas. Toda associação humana, segundo ele, manifesta forças contraditórias, encontrando-se imiscuída na luta entre harmonia e desarmonia. As tensões presentes em todas as esferas (individual, grupal e social), bem como entre as esferas, encontram-se no centro do jogo social, propiciando a decadência de formas de interação já cristalizadas e a ascensão de novas formas. Portanto, segundo Simmel, seja na investigação do processo de construção da intersubjetividade no mundo da vida cotidiana, seja na busca das formas da interação social, a matéria da sociação deve ser buscada nas relações entre os indivíduos. Tal interação não se faz sem riscos: o conflito encontra-se presente, ora aproximando, ora afastando grupos e indivíduos, tornando o encontro social uma experiência carregada de tensões, no qual a interação social também tem lugar na sua face aparentemente contraditória — dissociativa — do não encontro. Na sociabilidade simmeliana, há uma liberdade de fazer relações.

O modo pelo qual os grupos se fazem e desfazem e o modo pelo qual a conversação, surgida por mero impulso e oportunidade, começa, se aprofunda, se frouxa e termina, numa 'reunião social', fornece uma miniatura do ideal societário que poderia ser chamado a liberdade de se prender (Simmel, 1983:178). 
Emancipada de conteúdos, a sociabilidade para Simmel é uma forma de convivência com o outro liberada da seriedade e das obrigações da vida, transferindo esse caráter mais sério da vida para o jogo simbólico. Tal como a arte e o jogo, a sociabilidade existe por si mesma ou para a relação, a interação, o encontro. Para os jovens, as formas de sociabilidade parecem responder às suas necessidades de autonomia, liberdade e trocas afetivas.

Entendendo que parte da socialização dos jovens vem ocorrendo em espaços e tempos variados, com múltiplas referências culturais, é possível pensar os grupos de sociabilidade como articuladores de redes de significados e vivências que, num jogo de relações e interações, (re)constroem as identidades juvenis.

Para muitos esse contexto se traduz em apatia, desinteresse e individualismo. Porém, hoje, precisamos elaborar uma outra construção discursiva sobre os jovens, pois a situação juvenil na contemporaneidade constitui-se um fenômeno em curso: na estrutura da população brasileira, é a faixa etária com grande crescimento progressivo, apontando para um inchaço; como construção histórica situada no tempo e espaço, percebemos, hoje, uma dilatação da juventude que se coloca dos 12 aos 29 anos; é um segmento grande no cômputo eleitoral, mas tem uma história de participação política eleitoral recente; vivem uma mutação geracional não pensada há 50 anos, definida pela dificuldade de inserção no mercado de trabalho, escola, construção de projetos de vida e prolongamento do vínculo familiar, finalmente fazem do presente a dimensão privilegiada da existência.

Cada vez mais os jovens se vêem obrigados a realizar seus planos de vida sem as referências tradicionais. No entanto, os indivíduos tomam consciência de sua individualidade a partir do olhar do outro, num processo intersubjetivo em que eu sou para ti o que tu és para mim (Melucci, 1992). Portanto, quando se fala em identidade juvenil é preciso investigar onde os jovens estão construindo os nexos emocionais, onde e como estão buscando esse reconhecimento intersubjetivo e onde eles estão tomando consciência de sua individualidade, pois nos fazemos no encontro com o outro. Ou nas palavras de Melucci,

Sem a capacidade de permanecer ancorados em nós mesmos e de atravessar o vazio, não existe encontro, mas só benevolência, boa vontade precisamente. $\mathrm{O}$ encontro é a possibilidade de colocar lado a lado duas regiões de significado, dois campos de energias em freqüência diferente e de fazê-los vibrar juntos. $\mathrm{O}$ encontro é sim-patia, é com-paixão, sentir-com-o-outro. É a possibilidade de 
descobrir que o sentido não nos pertence e nos é dado no encontro, mas, ao mesmo tempo, só nós podemos produzi-lo (Melucci, 1992).

Lendo Melucci encontrei que nossa vida se desenvolve num mundo de objetos e processos da mente, marcada pela tensão entre o conteúdo e o limite da experiência. Para Melucci (1992) o círculo de Jade com um furo no centro, expressa essa tensão entre o limite e a possibilidade. «O furo aberto, o vazio, introduz no espaço existente uma pergunta que o ultrapassa, mas é também inscrito nos limites que a matéria lhe impõe. É nessa tensão que hoje encontramos perguntas sem respostas». Esse vazio que permanece e nos instiga a estudar jovens na contemporaneidade.

PORTO ALEGRE (BRASIL), MAIO 2004

\section{REFERÊNCIAS BIBLIOGRÁFICAS}

ARIÈs, PHILIPPE (1981): História social da criança e da família. Rio de Janeiro: Editora Guanabara.

Berger, Peter (1999): Perspectivas sociológicas: uma visão humanística. Petrópolis: Vozes.

— e THOMAS LUCKMANN (1985): A construção social da realidade. Petrópolis: Vozes.

CARRANO, PAUlo CESAR RodRigues (2002): Os jovens e a cidade: identidades e práticas culturais em Angra de tantos reis e rainhas. Rio de Janeiro: FAPERJ.

- (2001): «Jovens na cidade». Revista Trabalho e Sociedade, Ano 1, $\mathrm{N}^{\circ} 1$. Rio de Janeiro: IETS.

— e JUAREZ DAYRELL (2002): «Jovens no Brasil: difíceis travessias de fim de século e promessas de um outro mundo». Texto apresentado na 25a reunião da ANPED, anais 2002.

— e MÔNICA PEREgRINo (2003): «Jovens e escola: sentidos de presença». In: A escola e o mundo juvenil: experiências e reflexões. São Paulo: Ação educativa.

CAStro, MARY GARCia (2002): «O que dizem as pesquisas da UNESCO sobre juventude no Brasil: leituras singulares». Juventude, Cultura e Cidadania, Ano 21, Edição Especial 2002. Rio de Janeiro: Comunicações do ISER. 
CHARLOT, BERNARD (2000): Da relação com o saber: elementos para uma teoria. Porto Alegre: Artes Médicas Sul.

DuRAND, Olga CelestinA DA Silva (2000): «Jovens da Ilha de Santa Catarina: sociabilidade, socialização». Tese Doutorado. São Paulo: Faculdade de Educação da USP.

FORTUNA, CARLOS (1997): "As cidades e as identidades: narrativas patrimônios e memórias». Revista Brasileira de Ciências Sociais, Vol. 12, No33.

Freire, PaUlo (1999): Pedagogia da autonomia: saberes necessários à prática educativa. São Paulo: Paz e Terra.

FURTER, PIERRE (1987): Educação e vida. Petrópolis: Vozes.

GIDDENS, ANTHONY (2002): Modernidade e identidade. Rio de Janeiro: Jorge Zahar.

HERSCHMANN, MicAEL (2002): O funk e o hip-hop invadem a cena. Rio de Janeiro: Editora UFRJ.

KEMP, KENIA (1993): «Grupos de estilo jovens; o rock underground e as práticas (contra)culturais dos grupos 'punk' e ‘trash' em São Paulo». Dissertação Mestrado. São Paulo: Departamento de Antropologia da UNICAMP.

LEVI, GIOVANNI e JEAN-CLAUdE SCHMitT (org.) (1996): História dos jovens. Vol. 1. Da antigüidade à era moderna. São Paulo: Companhia das Letras.

LLORET, CATERINA (1998): "As outras idades ou as idades do outro». In: JoRge LARROSA e NURIA PÉREZ DE LARA (org.): Imagens do outro. Petrópolis: Vozes.

MARGULIS, MARIO e MARCELO URRESTI (1998): «La construcción social de la condición juvenil». In: HUMBERTO CUBIDES et al. (org.): Viviendo a toda: jóvenes, territorios culturales y nuevas sensibilidades. Santafé de Bogotá: Siglo del Hombre Editores, Departamento de Investigaciones Universidad Central.

MelucCi, Alberto (2001): A invenção do presente: movimentos sociais nas sociedades complexas. Rio de Janeiro: Vozes.

- (1997): «Juventude, tempo e movimentos sociais». Revista Brasileira de Educação No5-6. São Paulo: ANPED.

- (1992): O jogo do eu: a mudança de si mesmo na sociedade globalizada. Editora Feltrinelli.

PAIS, JosÉ MACHADO (2001): Ganchos, tachos e biscates: jovens, trabalho e futuro. Porto: Ambar. (1993): Culturas juvenis. Lisboa: Imprensa Nacional Casa da Moeda. 
PÉREZ ISLAS, JosÉ ANTONIO (2001): «Pro(diá)logo, políticas de juventud del nuevo siglo: para mirar lo que vemos». JOVENes, Revista de Estudios sobre Juventud Nº11. México: IMJ.

PoCHMANN, MARCIO (2000): «Emprego e desemprego juvenil no Brasil: as transformações nos anos 1990». Movimento Nº 1 . Revista da Faculdade de Educação da Universidade Federal Fluminense. Rio de Janeiro: DP\&A.

SiMMEL, GEORG (1983): «Sociabilidade: um exemplo de sociologia pura ou formal». EVARISTO MORAIS FILHO (org.): Simmel. São Paulo: Ática.

SPOSITO, MARÍLIA (2000): «Algumas hipóteses sobre as relações entre movimentos sociais, juventude e educação». Revista Brasileira de Educação Nº13. São Paulo: ANPED.

— (1997): "Considerações sobre a tematização social da juventude no Brasil». Revista Brasileira de Educação N5-6. São Paulo: ANPED.

VALENZUELA ARCE, JosÉ MANUEL (1999): Vida de barro duro: cultura popular juvenil e grafite. Rio de Janeiro: Editora UFRJ. 